\title{
Influence of Parental Attachment on Adolescent Identity Styles Development
}

\author{
Jimoh, G.O. ${ }^{1} \quad$ Eni-Olorunda, J.T(Ph.D) ${ }^{2} \quad$ Adubi K.O.(Ph.D) ${ }^{2} \quad$ Afolabi W.A.O.(Ph.D) ${ }^{2}$ \\ 1.Department of Home Economics, Federal College of Education, Abeokuta. Ogun State, Nigeria \\ 2.Department of Home Science and Management, Federal University of Agriculture, Abeokuta. P.M.B 2240. \\ Abeokuta. Ogun State, Nigeria
}

\begin{abstract}
Identity formation has been identified as one of the problems associated with socialization process during adolescence. Adolescents who receive proper encouragement through personal exploration will emerge from this stage with a strong sense of self and the ones who remain unsure of their beliefs and desires will feel insecure and confused. This study assessed the influence of parental attachment on identity style development among students in public senior secondary schools in Ogun state. A multistage sampling technique was used to select 396 adolescents from four geo-political zones in Ogun state. Adapted questionnaires (Inventory of Parent and Peer Attachment and Identity Style Inventory (IPPA) and Identity Style Inventory (ISI-) were used to elicit information from the respondents on parental attachment and identity styles. Data were analysed using multiple regression. The study was able to establish that maternal and paternal attachment fosters informative identity style (standardized beta weight of .259 and .268) and normative identity styles (standardized beta weight of .206 and .224) in adolescents but not diffuse avoidant identity style (standardized beta weight of .101 and -.037). The study therefore recommends Programs should be developed which will aim at sensitizing parents on the neurocognitive, social and emotional changes that occurs during adolescence and how their continued responsiveness to their adolescent needs impact their identity development.
\end{abstract}

Keywords: attachment, normative, informative, diffuse-avoidant

DOI: $10.7176 /$ RHSS/11-2-05

Publication date: January $31^{\text {st }} 2021$

\section{Introduction}

Adolescence is seen as a stage of development filled with opportunities and risk. In the field of human development, adolescence is recognised as the second major development next in significance to early childhood development. This is because it is a period of biological, cognitive and social change and it is usually associated with various risk-taking behaviors and health related problems such as eating disorders , substance abuse and dependence, risky sexual behaviour, antisocial and delinquent activity, depression and school dropout (Dubois et al., 2013). Questions are been raised in recent years on the influence of parents on adolescent adjustment. Some researchers are of the opinion that parents make little or no difference in how their adolescents children navigate this period since data had shown that peer influence govern this period (Larson et al., 1996). Contrary to this opinion, there is growing research evidence that parents do contribute significantly during this period and that this contribution can be reflected in their attachment bond with their child (Markiewicz, 2006). Attachment is a deep and enduring emotional bond that connects one person to another across time and space (Ainsworth in Gandhi, 2019). Successful transition from adolescence to adulthood cannot be achieved through detachment from parents but by secure attachment and emotional connectedness with parents (Moretti et al., 2004).

Erikson's (1956) describes identity as the crowning achievement of adolescence as teenagers discovers who they are and addresses issues related to their sense of self. The identity formed during this period guides each subsequent stage of psychosocial development. Berzonsky in Kaylin (2013) defined Identity-processing style as the way in which an individual digest, interprets, and utilizes identity -relevant information. Berzonsky identified three categories of identity-processing styles: informational, normative, and diffusive avoidant. Before making any one commitment, individuals with an informational processing style enthusiastically seek out applicable identity information as self-motivated explorers. Individual who adheres to this, make decisions swiftly, conscientious, extroverted, open-minded, are less prone to panic.

The normative processing style is characterized by the tendency to be easily influenced by others, especially those of particular importance to the individual (e.g., parents, teachers, counsellors, peers, etc.) and they tend to adopt other's viewpoints, beliefs, and norms. Finally, diffuse-avoidant individuals are most likely to adjourn the processing and commitment of any identity-relevant information. In other words, they attempt to avoid making definite decisions related to who they are (Kaylin, 2013).

The purpose of this study was to determine the influence of parental attachment (maternal and paternal) on adolescent identity style development 


\section{Hypothesis}

HO1: There is no significant relationship between informative identity style and parental (maternal and paternal) attachment

HO2: There is no significant relationship between normative identity style and parental (maternal and paternal) attachment

HO3: There is no significant relationship between diffuse avoidant identity style and parental (maternal and paternal) attachment

\section{Methodology}

\subsection{Design}

The study employed the cross sectional and descriptive design so as to assess parental attachment influence on adolescents identity style development. The study was carried out in Ogun state

\subsection{Population and Sampling}

The population of the study consisted of 170,685. A multistage sampling technique was used to select 396 adolescents (207 females and 189 males) from the four geo-political zones in Ogun state which include Remo, Ijebu, Yewa and Egba.

\subsection{Instrument for Data Collection}

Questionnaires was used to collect data and was adapted from Inventory of Parent and Peer Attachment (IPPA; Armsden \& Greenberg, 1987) and Identity Style Inventory-3 (ISI-3; Berzonsky, 1992b). The IPPA was developed to measure attachment in older adolescents and ISI-3 was developed to assess three social-cognitive styles related to identity exploration and how they resolve personal issues and utilize decision making strategies.. In order to make the instrument to suit the local situation, it was modified by reducing the number of items in the instrument and reframing some of the statements.

\subsection{Validation of Instrument}

The research instrument was subjected to face and content validity. Test re-test method was employed in determining the reliability of the questions used in the questionnaire. Pearson Product Moment Correlation of Inventory of Parent and Peer Attachment (IPPA) for the maternal(IPPAM) was found to be 0.77 while for the paternal(IPPAP) was found to be 0.81 while that of the ISI-3 was found to be 0.86 .

\section{Results}

In testing this hypothesis, multiple regression analysis was used to analyse data. The result of the analysis is presented in below.

HO1: There is no significant relationship between informative identity style and parental (maternal and paternal) attachment

Table 1: Correlations between maternal and paternal attachment on informative identity style.

\begin{tabular}{|c|c|c|c|c|}
\hline & & INFORMATIVE & IPPAP & IPPAM \\
\hline \multirow[t]{3}{*}{ Pearson Correlation } & INFORMATIVE & 1.000 & .350 & .356 \\
\hline & IPPAP & .350 & 1.000 & .338 \\
\hline & IPPAM & .356 & .338 & 1.000 \\
\hline \multirow[t]{3}{*}{ Sig. (1-tailed) } & INFORMATIVE & .000 & .000 & \\
\hline & IPPAP & .000 & & .000 \\
\hline & IPPAM & .000 & .000 & . \\
\hline
\end{tabular}

\section{$\mathrm{N}=396$}

Table 1 shows the interaction coefficient among the dependent variables. It could be seen that r-cal of .350, $\mathrm{P}=0.000$ which is less than 0.05 therefore there is a significant relationship between Informative identity style and paternal attachment, $\mathrm{r}$ cal $.356 \mathrm{P}=0.000$ which is less than 0.05 . Therefore there is a significant relationship between Informative identity style and Maternal attachment.

In order to determine the variation accounted for in the parental attachment as a result of informative identity style, table 2 is presented. 
Table 2: ANOVAa table on the variation in the informative in the informative identity style as a result of parental attachment.

\begin{tabular}{llllll}
\hline Model & Sum of Squares & df & Mean Square & F & Sig. \\
\hline 1 Regression & 601.491 & 2 & 300.746 & 44.865 & $.000 \mathrm{~b}$ \\
Residual & 2634.415 & & 393 & 6.703 & \\
Total & 3235.907 & & 395 & & \\
\hline
\end{tabular}

a Dependent Variable: INFORMATIVE

b Predictors: (Constant), IPPAM TOTAL, IPPAP TOTAL

$\mathrm{R}^{\wedge} 2=.186$ Adjusted $\mathrm{R}^{\wedge} 2=.182$

Table 2 shows that the variations in informative identity style jointly accounted for by the parental attachment was $18.6 \%$ leaving about $81.4 \%$ unaccounted for.

This was statistically significant at 0.05 alpha level since the F calculated (44.865) $\mathrm{P}=0.000$ which is less than 0.05 given 2/393 degrees of freedom. Therefore, there is a significant relationship between parental attachment and informative identity style.

To determine the independent contribution of each of the dependent variable table 3 is presented.

Table 3: Coefficients

\begin{tabular}{llllll}
\hline Model & \multicolumn{2}{l}{$\begin{array}{l}\text { Unstandardized } \\
\text { Coefficients }\end{array}$} & $\begin{array}{c}\text { standardized } \\
\text { coefficient }\end{array}$ & & sig \\
\hline 1(Constant) & $\mathrm{B}$ & Std. Error & Beta & $\mathrm{t}$ & .000 \\
IPPAP & 10.153 & .998 & & 10.176 & .000 \\
IPPAM & .141 & .026 & .259 & 5.357 & .000 \\
\hline
\end{tabular}

a Dependent Variable: INFORMATIVE

Table 3 shows that paternal attachment and maternal attachment contributed significantly to informative identity style as evident from the standardized beta weight of .259 and .268 .

Therefore, the null hypothesis (HO1) was rejected

HO2: There is no significant relationship between informative identity style and parental (maternal and paternal) attachment

Table 4: Correlation between maternal and paternal attachment on normative identity style

\begin{tabular}{llcll}
\hline & & NORMATIVE & IPPAP & IPPAM \\
\hline Pearson Correlation & NORMATIVE & 1.000 & .282 & .294 \\
& IPPAP & .282 & 1.000 & .338 \\
Sig. (1-tailed) & IPPAM & .294 & .338 & 1.000 \\
& NORMATIVE &. & .000 & .000 \\
& IPPAP & .000 &. & .000 \\
\hline
\end{tabular}

$\mathrm{N}=396$

Table 4 shows the interaction coefficient among the dependent variables. It could be seen that $\mathrm{r}$-cal is .282, $\mathrm{P}$ $=0.000$ which is less than 0.05 therefore there is a significant relationship between Normative identity style and paternal attachment. $\mathrm{r}$-cal $.294 \mathrm{P}=0.000$ which is less than 0.05 therefore there is a significant relationship between Normative identity style and Maternal attachment.

In order to determine the variation accounted for in the parental attachment as a result of informative identity style, table 5 was presented.

Table 5: ANOVAa table of the variation in the normative identity style as a result of parental attachment

\begin{tabular}{llllll}
\hline Model & Sum of Squares & df & Mean Square & F & Sig. \\
\hline 1 Regression & 806.567 & 2 & 403.283 & 27.756 & $.000 \mathrm{~b}$ \\
Residual & 5710.188 & & 393 & 14.530 & \\
Total & 6516.755 & & 395 & & \\
\hline
\end{tabular}

a Dependent Variable: NORMATIVE

b Predictors: (Constant), IPPAM TOTAL, IPPAP TOTAL

$\mathrm{R}^{\wedge} 2=.124$ Adjusted $\mathrm{R}^{\wedge} 2=.119$

Table 5 shows that the variations in normative identity style jointly accounted for by the parental attachment was $12.4 \%$ leaving about $87.6 \%$ unaccounted for.

This was statistically significant at 0.05 alpha level since the F calculated (27.756) $\mathrm{P}=0.000$ which is less than 0.05 given $2 / 393$ degrees of freedom. Therefore, there is a significant relationship between parental attachment and normative identity style.

To determine the independent contribution of each of the dependent variable table 6 was presented. 
Table 6: Coefficients

\begin{tabular}{llllll}
\hline Model & \multicolumn{2}{l}{$\begin{array}{l}\text { Unstandardized } \\
\text { Coefficients }\end{array}$} & $\begin{array}{c}\text { standardized } \\
\text { coefficient }\end{array}$ & \\
\hline & $\mathrm{B}$ & Std. Error & Beta & $\mathrm{t}$ &. $\mathrm{sig}$ \\
\hline 1(Constant) & 8.037 & 1.469 & & 5.471 & .000 \\
IPPAP & .160 & .039 & .206 & 4.105 & .000 \\
IPPAM & .211 & .047 & .224 & 4.462 & .000 \\
\hline
\end{tabular}

a Dependent Variable: NORMATIVE

Table 6 revealed that paternal attachment and maternal attachment contributed significantly to normative identity style as evident from the standardized beta weight of .206 and .224 .

Therefore, the null hypothesis (Ho2) was rejected.

HO3: There is no significant relationship between diffuse avoidant identity style and parental (maternal and paternal) attachment

Table 7: Correlations between maternal and paternal attachment on Diffusive Avoidant identity style

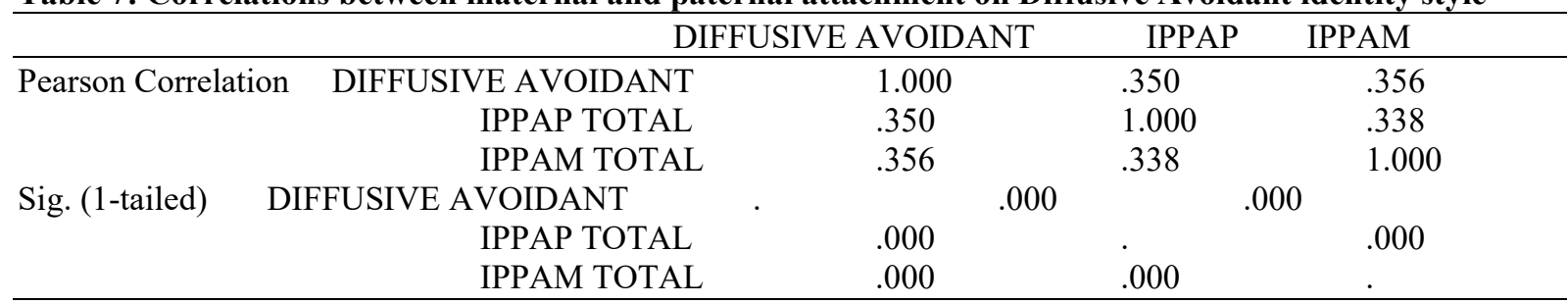

$\mathrm{N}=396$

Table 7 shows the interaction coefficient among the dependent variables. It could be seen that $\mathrm{r}$-cal is $.350, \mathrm{P}$ $=0.000$ which is less than 0.05 therefore there is a significant relationship between Diffusive Avoidant identity style and paternal attachment, $\mathrm{r}$ cal $.356 \mathrm{P}=0.000$ which is greater than 0.05 therefore there is no significant relationship between Diffusive Avoidant identity style and Maternal attachment.

In order to determine the variation accounted for in the parental attachment as a result of Diffusive Avoidant identity style, table 8 is presented.

Table 8: ANOVAa table on the variation in the informative in the Diffusive Avoidant identity style as a result of parental attachment

\begin{tabular}{llllcc}
\hline Model & Sum of Squares & df & Mean Square & F & Sig. \\
\hline & & & & & \\
1 Regression & 62.350 & 2 & 31.175 & 1.775 \\
& $.171 \mathrm{~b}$ & & & \\
Residual & 6901.822 & 393 & 17.562 & & \\
Total & 6964.172 & 395 & & & \\
\hline
\end{tabular}

a Dependent Variable: DIFFUSIVE AVOIDANT

b Predictors: (Constant), IPPAM TOTAL, IPPAP TOTAL

$\mathrm{R}^{\wedge} 2=.009$ Adjusted $\mathrm{R}^{\wedge} 2=.004$

Table 8 revealed shows that the variations in Diffusive Avoidant identity style jointly accounted for by the parental attachment was $0.9 \%$ leaving about $99.1 \%$ unaccounted for.

This was statistically significant at 0.05 alpha level since the $F$ calculated (1.775) $\mathrm{P}=.171$ which is greater than 0.05 given $2 / 393$ degrees of freedom. Therefore, there is no significant relationship between parental attachment and Diffusive Avoidant identity style.

To determine the independent contribution of each of the dependent variable table 3.9 is presented.

Table 3.9: Coefficients

\begin{tabular}{llllll}
\hline Model & \multicolumn{2}{l}{$\begin{array}{l}\text { Unstandardized } \\
\text { Coefficients }\end{array}$} & $\begin{array}{c}\text { standardized } \\
\text { coefficient }\end{array}$ & & \\
\hline & $\mathrm{B}$ & Std. Error & Beta & $\mathrm{t}$ &. sig \\
\hline 1(Constant) & 13.151 & 1.615 & & 8.143 & .000 \\
IPPAP & .081 & .043 & .101 & 1.883 & .060 \\
IPPAM & -.036 & .052 & -.037 & -.691 & .490 \\
\hline
\end{tabular}

a Dependent Variable: DIFFUSIVE AVOIDANT

Evidenced from table 9 shows that paternal attachment and maternal attachment does not contribute significantly to Diffusive Avoidant identity style as evident from the standardized beta weight of .101 and -.037 Therefore, the null hypothesis (Ho3) was accepted. 


\section{Discussion}

The relationship between attachment and identity formation is still unclear within the field of developmental psychology because previous research has produced conflicting results. There is little literature on how attachment relates to identity style perhaps due to the reasons cited in Ávila et al.(2012): nonfamily influence becomes more prominent as individuals age. Peers rather than parents become larger factors in identity development in late adolescence.

The result from this study revealed that both maternal and paternal attachment fosters informative and normative identity style in adolescent but does not foster diffuse avoidant identity style. This result tallies with the work of Campbell et al (1984) who suggested that a combination of emotional attachment to parents and the encouragement of independence are associated with identity achievement and moratorium (by extensioninformative), adolescents who were classified as foreclosed (by extension- normative) reported the highest levels of affection toward their parents, and those classified as diffused reported the lowest.

In the same vein, Kaylin (2013) concludes that maternal attachment was found to significantly predict the normative identity style; however, it seems that paternal attachment had no such predictive value. The result of this study is contrary to this as both maternal and paternal attachment was found to be significantly related to normative identity style.

\section{Conclusion}

From the result above, the following conclusion was drawn

There is a relationship between informative identity style and adolescents paternal and maternal attachment There is a relationship between normative identity style and adolescents paternal and maternal attachment There is no relationship between diffuse avoidant identity style and adolescents paternal and maternal attachment

\section{Recommendation}

Parents should not only provide their adolescent children with basic needs but should also create time to express affection for identity development to occur normally because attachment provides a secured base for adolescent to explore their talent and experiences as such experiences prepare adolescent to become socially connected with others and to learn how to be caregivers themselves. Adolescents who adopt diffusive avoidant style should be encouraged to explore before making decision and commitment. Programs should be developed which will aim at sensitizing parents on the neurocognitive, social and emotional changes that occurs during adolescence and how their continued responsiveness to their adolescent needs impact their identity development.

\section{References}

Ávila, M., Cabral, J., \& Matos, P. (2012). Identity in university students: The role of parental and romantic attachment. Journal of Adolescence, 35(1), 133-142.

Campbell, E., Adams, G. R., \& Dobson, W. R. (1984). Familial correlates of identity formation in late adolescence: A study of the predictive utility of connectedness and individuality in family relations. Journal of Youth and Adolescence, 13(6), 509-525.

Dubois-Comtois K, Cyr C, Pascuzzo K, Lessard M (2013) Attachment Theory in Clinical Work with Adolescents. Journal of Child and Adolescent Behaviour 1:111. doi:10.4172/2375-4494.1000111

Erikson, E. (1956). The problem of ego identity. Journal of the American Psychoanalytic Association, 4, 56-121.

Gandhi, A., Luyckx, K., Molenberghs, G. et al. Maternal and peer attachment, identity formation, and non-suicidal self-injury: a longitudinal mediation study. Child Adolesc Psychiatry Ment Health 13, 7 (2019). https://doi.org/10.1186/s13034-019-0267-2

Kaylin Ratner (2014). The role of parenting and attachment in identity style development. The University Of Central Florida Undergraduate Research Journal Vol. 7.1: 15-26

Larson RW, Richards MH, Moneta G (1996) Changes in adolescents' daily interactions with their families from ages 10 to 18\: Disengagement and transformation. Developmental Psychology 32: 744-754

Markiewicz D, Lawford H, Doyle AB, Haggart N (2006) Developmental differences in adolescents' and young adults' use of mothers, fathers, best friends, and romantic partners to fulfill attachment needs. Journal of Youth and Adolescence 35: 127-140.

Moretti MM, Peled M. (2004) Adolescent-parent attachment: Bonds that support healthy development. Paediatr Child Health 2004;9(8):551-555. 